\title{
Body Temperature Regulation in Rats during Exercise of Various Intensities at Different Ambient Temperatures
}

\author{
Hideto Tanaka, Motoko Yanase, and Teruo Nakayama \\ Department of Physiology, Osaka University Medical School, \\ Kita-ku, Osaka, 530 Japan
}

\begin{abstract}
We examined the relationship between body temperature, tail vasomotor response, and work intensity at different ambient temperatures in rats, using a treadmill and continuously measuring oxygen uptake during exercise. At an ambient temperature $\left(T_{\mathrm{a}}\right)$ of $24^{\circ} \mathrm{C}$, rectal temperature $\left(\mathrm{T}_{\mathrm{re}}\right)$ at the beginning of tail vasodilation during exercise increased in proportion to work intensity. After tail vasodilation $T_{\text {re }}$ remained steady, and at the end of $30 \mathrm{~min}$ exercise $T_{\mathrm{re}}$ level was proportional to work intensity. At $T_{\mathrm{a}}$ of $14^{\circ} \mathrm{C}, T_{\mathrm{re}}$ at the end of exercise was slightly higher than at $24^{\circ} \mathrm{C}$, and was higher at higher work intensities. At $T_{\mathrm{a}}$ of $4^{\circ} \mathrm{C}, T_{\text {re }}$ rose slower during exercise than at higher $T_{\mathrm{a}} \mathrm{s}$ and even dropped at relatively low work intensities. Tail vasodilation did not occur in most cases. At $T_{\mathrm{a}}$ of $34^{\circ} \mathrm{C}, T_{\text {re }}$ rose continuously during exercise. These data indicate that body temperature of rats during exercise rises in proportion to work intensity, but the extent of body temperature rises differs according to $T_{\mathrm{a}}$.
\end{abstract}

Key words : rectal temperature, tail vasomotor response, work intensity, ambient temperature, rat.

Deep body temperature in man rises during exercise in proportion to work intensity, irrespective of ambient temperature $\left(T_{\mathrm{a}}\right)$ of 5 to $25^{\circ} \mathrm{C}$ (NIELSEN, 1938). The physiological mechanism of this exercise-induced hyperthermia is not clear. Although man has been given detailed attention in many studies, methodological limitations have necessitated animal studies as well.

The rat, extensively used as an experimental animal in acute and chronic studies, has made a great contribution to elucidate central nervous mechanism for thermoregulation. Since the rat, however, does not sweat or pant (AdOLF, 1947), and moreover cannot spread saliva effectively during exercise, how is body temperature of the rats during exercise influenced by work intensity and $T_{\mathrm{a}}$ ? Although some reports have investigated the relationship between work intensity

Received for publication January 13, 1988 
and deep body temperature at a given $T_{\mathrm{a}}$ (THOMPSON and STEvenson, 1965; Gollnick and IAnuzzo, 1968; Wilson et al., 1978; Sonne and Galbo, 1980; HarRi et al., 1982), the relationship remains obscure. Since treadmill speed has been used to indicate work intensity in most studies, individual differences among the animals may have been responsible for discrepancies in results. Core temperature during exercise in man was set according to the relative work load of the individual and not to the absolute work load performed (SAltin and Hermansen, 1966). A similar consideration should be applied to exercising rats. A relationship between deep body temperature during exercise and $T_{\mathrm{a}}$ has also been reported (HART and JANSKY, 1963), but how work intensity might influence this relation is unclear.

The purpose of this study was to clarify the relationships among work intensity, tail vasomotor response, and deep body temperature in rats during treadmill running. We also investigated the influence of $T_{\mathrm{a}}$ on this relation.

\section{MATERIALS AND METHODS}

Experimental apparatus. A motor-driven treadmill could operate at any speed between 2 and $50 \mathrm{~m} / \mathrm{min}$ in a stable manner. The belt speed could be kept consistent because a direct-current motor was connected directly to the driving wheel and was controlled by a servomechanism. The treadmill itself was situated inside an acrylic metabolic chamber (inside dimensions, $35 \times 8 \times 18 \mathrm{~cm}$ ), but the motor lay outside.

Oxygen uptake $\left(\dot{V}_{\mathrm{O}_{2}}\right)$ was measured by an open-circuit system. Atmospheric air was led into the box at the rear of the treadmill. Outgoing air passed through an absorption pump and a flow meter. When flow rate was adjusted to $5 \mathrm{l} / \mathrm{min}$ (ATPS) in preliminary work, no air inside the chamber leaked out and measurements were stable. One hundred $\mathrm{ml} / \mathrm{min}$ of this flow was passed through an oxygen analyzer (Toray, LC-700E). $\dot{V}_{\mathrm{O}_{2}}$ was calculated by determining the relation between difference of $\mathrm{O}_{2} \%$ (inlet $\mathrm{O}_{2} \%$ - outlet $\mathrm{O}_{2} \%$ ) and air flow. The response time of the system following injection of a marker gas was $50 \mathrm{~s}$. This delay of $\mathrm{O}_{2}$ measurement was corrected after the end of each experiment.

Evaporative water loss (EWL) was assessed by measuring absolute humidity (AH) with a hygrometer (Sibaura, SM-360) in the metabolic chamber. EWL was calculated according to change in $\mathrm{AH}$ and air flow.

Rectal $\left(T_{\mathrm{re}}\right)$ and tail skin $\left(T_{\text {tail }}\right)$ temperatures were measured by $\mathrm{Cu}-\mathrm{Co}$ thermocouples. $T_{\text {re }}$ and $T_{\text {tail }}$ were continuously recorded by a chart recorder.

Animals, training, and $\dot{V}_{\mathrm{O}_{2} \max }$ test. Experiments were performed on male Wistar rats with initial body weights of approximately $100 \mathrm{~g}$. These rats were housed in a cage maintained at an air temperature of $25^{\circ} \mathrm{C}$ and had free access to food and water. Lighting was controlled automatically for a $0600-1800 \mathrm{~h}$ light cycle.

The rats were trained to get accustomed to the treadmill running in a climatic room at a $T_{\mathrm{a}}$ of $24^{\circ} \mathrm{C}$. Rats were induced to run by mild electrical stimulation. If the rat stopped running and its feet touched an electrified grid at the rear of the treadmill, the rat received an electrical shock as long as the feet remained in contact 
with the grid. Training consisted of 2 days/week for 6 weeks. The rats ran initially for $10 \mathrm{~min} /$ day at $10 \mathrm{~m} / \mathrm{min}$. Thereafter, duration and running speed of the exercise was increased gradually and they ran continuously for $30 \mathrm{~min}$ at $15 \mathrm{~m} / \mathrm{min}$.

$\dot{V}_{\mathrm{O}_{2} \max }$ was examined twice, before and after a series of experiments, in each rat that could run stably in the above training. Prior to each $\dot{V}_{\mathrm{O}_{2} \max }$ test, the rat was weighed and then placed in the treadmill chamber. The rat first exercised for 5$10 \mathrm{~min}$ at $10 \mathrm{~m} / \mathrm{min}$, rested $3 \mathrm{~min}$, and then exercised at $15 \mathrm{~m} / \mathrm{min}$. The running speed was increased $2.5 \mathrm{~m} / \mathrm{min}$ every $3 \mathrm{~min}$ until the rat could no longer maintain pace with the treadmill. The highest $\dot{V}_{\mathrm{O}_{2}}$ recorded during the final $30 \mathrm{~s}$ of every $3 \mathrm{~min}$ running period was taken as $\dot{V}_{\mathrm{O}_{2} \max }$.

Experimental conditions.

1. Procedure 1: We measured $T_{\text {re }}, T_{\text {tail }}, \dot{V}_{\mathrm{O}_{2}}$, and EWL at one steady state during running for $30 \mathrm{~min}$ with $T_{\mathrm{a}}$ at $24^{\circ} \mathrm{C}$. At the start of each experiment, thermocouple probes for measuring $T_{\text {re }}$ and $T_{\text {tail }}$ were attached. $T_{\text {re }}$ was measured with a thermocouple inserted $6 \mathrm{~cm}$ into the anus. $T_{\text {tail }}$ was measured with a thermocouple taped to the dorsal surface of the tail about $6 \mathrm{~cm}$ distal to its base. The rat was placed in the treadmill chamber, set in a climatic room at $T_{\mathrm{a}}$ of $24^{\circ} \mathrm{C}$ with relative humidity at $54 \pm 4 \%$. Thirty min later, $\dot{V}_{\mathrm{O}_{2}}, T_{\text {re }}, T_{\text {tail }}$, and $\mathrm{AH}$ were measured for $10 \mathrm{~min}$ and then the rat ran for $30 \mathrm{~min}$ at running speed of 3 to $30 \mathrm{~m} / \mathrm{min}$. Average $\dot{V}_{\mathrm{O}_{2}}$ during exercise was calculated from the 10 th to the 30 th $\mathrm{min}$ of the treadmill run, and we estimated the relative work intensity for each run on the basis of this average $\dot{V}_{\mathrm{O}_{2}}$. After the $30 \mathrm{~min}$ of running, further measurements were taken over a $30 \mathrm{~min}$ recovery period. The ordering of the running speed was randomized and each rat was tested 5-8 times. All experiments were performed between 1:00 and 6:00 p.m.

2. Procedure 2: This experimental series, to examine the effect of $T_{\mathrm{a}}$, was performed at $T_{\mathrm{a}} \mathrm{s}$ of 4,14 , and $34^{\circ} \mathrm{C}$, with relative humidity at $50-70 \%$. The experimental procedure was otherwise the same as in Procedure 1. The rats experienced $T_{\mathrm{a}} \mathrm{s}$ of 4 and $14^{\circ} \mathrm{C}$ in random order and lastly $34^{\circ} \mathrm{C}$.

Statistics. Statistical evaluation of the result was performed by linear regression and analysis of variance, with further analysis by a paired Student's $t$-test where appropriate. Data were considered statistically significant if $p<0.05$. The results are expressed as mean value \pm S.D.

\section{RESULTS}

Of 20 rats undergoing the treadmill running training, 13 exhibited stable running at a speed of $15 \mathrm{~m} / \mathrm{min}$ for $30 \mathrm{~min}$. Since the other 7 frequently received electrical shocks while running, they were excluded from the experiments. Mean body weight at the $\dot{V}_{\mathrm{O}_{2} \max }$ test was $302 \pm 16 \mathrm{~g}$ and mean $\dot{V}_{\mathrm{O}_{2} \max }$ was $69.5 \pm 4.3 \mathrm{ml}$ / (min $\cdot \mathrm{kg}$ ) in 13 rats. $\dot{V}_{\mathrm{O}_{2} \max }$ for each rat was the same in two tests. 


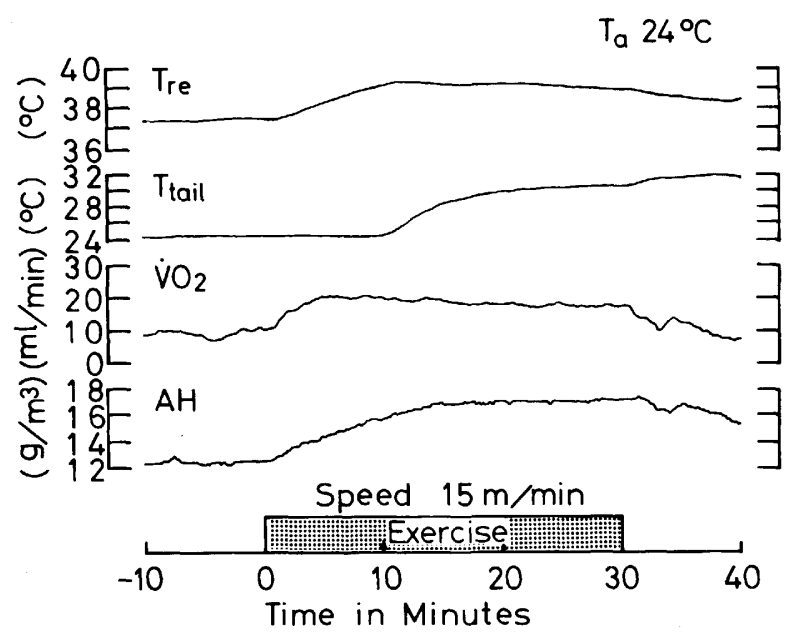

Fig. 1. Rectal temperature $\left(T_{\mathrm{re}}\right)$, tail skin temperature $\left(T_{\mathrm{tai}}\right)$, oxygen uptake $\left(\dot{V}_{\mathrm{O}_{2}}\right)$, and absolute humidity (AH) at rest, during exercise for $30 \mathrm{~min}$, and in recovery, at an ambient temperature of $24^{\circ} \mathrm{C}$.

\section{Running at $24^{\circ} \mathrm{C}$}

In Procedure 1 five rats performed 34 trials. Figure 1 shows a typical result. At rest, $T_{\text {re }}$ was $37.4^{\circ} \mathrm{C}$ and $T_{\text {tail }}$ was only a little higher than $T_{\mathrm{a}} . T_{\text {re }}$ decreased a little just after running began, and then it began to rise. When $T_{\text {re }}$ reached $39.0^{\circ} \mathrm{C}, T_{\text {tail }}$ began to rise gradually. At nearly the same time, $T_{\text {re }}$ rose less rapidly, eventually attaining a steady level. AH rose during exercise. After the exercise, $T_{\text {tail }}$ rose still more and $T_{\text {re }}$ dropped gradually.

Figure $2 \mathrm{~A}$ shows the relation between $T_{\mathrm{re}}$ and relative work intensity $\left(\dot{V}_{\mathrm{O}_{2} \max } \%\right.$ ) at the time $T_{\text {tail }}$ began to rise. Mean $T_{\text {re }}$ (broken line) at rest before exercise was $37.5 \pm 0.4^{\circ} \mathrm{C}$ and mean $\dot{V}_{\mathrm{O}_{2}}$ at rest was $24.7 \pm 3.3 \mathrm{ml} /(\mathrm{min} \cdot \mathrm{kg}) . T_{\mathrm{re}}$ at the beginning of $T_{\text {tail }}$ rise in 34 trials increased in proportion to work intensity, reaching $39.3^{\circ} \mathrm{C}$ at $75 \% \dot{V}_{\mathrm{O}_{2} \max }$ and leveling off at higher work intensities. The regression line in the range from 45 to $75 \% \dot{V}_{\mathrm{O}_{2} \max }$ was $Y=35.77+0.048 X(r=0.83)$. Degree of the $T_{\text {tail }}$ rise, however, was independent of work intensity. Figure $2 \mathrm{~B}$ shows how $T_{\text {re }}$ related to work intensity at the end of $30 \mathrm{~min}$ of exercise. The $T_{\mathrm{re}}$, as at the beginning of $T_{\text {tail }}$ rise, was proportional to work intensity, reaching a maximum at $75 \% \dot{V}_{\mathrm{O}_{2} \max }$. The regression line for this relation in the range of $45-75 \% \dot{V}_{\mathrm{O}_{2} \max }$ was $Y=35.22+0.048 X(r=0.73)$. EWL, calculated from change in AH over the $30 \mathrm{~min}$ exercise period, is plotted against work intensity in Fig. 3. Mean EWL at rest was $24.3 \pm 7.8 \mathrm{mg} /(\mathrm{min} \cdot \mathrm{kg})$. During $30 \mathrm{~min}$ of exercise EWL increased in proportion to work intensity.

\section{Running at 4,14 , and $34^{\circ} \mathrm{C}$}

Eight rats were used for Procedure 2. Thirty-eight trials were performed at a $T_{\mathrm{a}}$ 
$\mathrm{T}_{\mathrm{a}} 24^{\circ} \mathrm{C}$

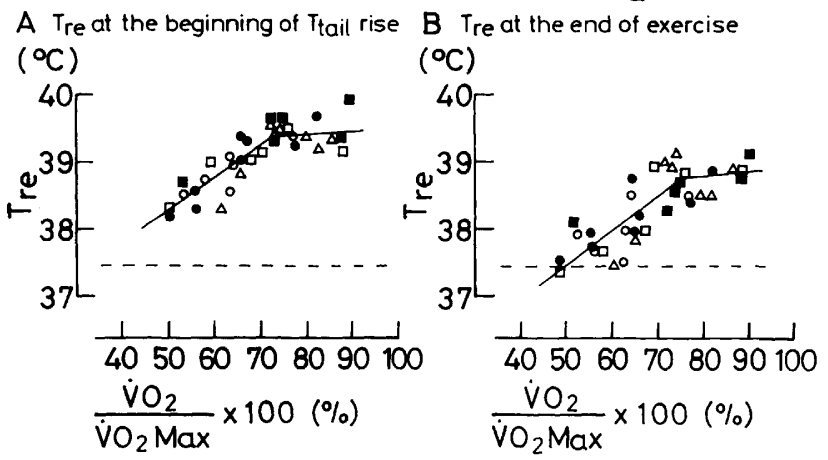

Fig. 2. Relation of rectal temperature $\left(T_{\mathrm{re}}\right)$ at the beginning of tail skin temperature $\left(T_{\text {tail }}\right)$ rise $(\mathrm{A})$, and at the end of 30 min exercise (B) to oxygen uptake $\left(\dot{V}_{\mathrm{O}_{2}}\right)$, normalized to individual maximal oxygen uptake $\left(\dot{V}_{\mathrm{O}_{2} \max }\right)$, at an ambient temperature of $24^{\circ} \mathrm{C}$. Each symbol indicates the same rat. Broken lines indicate mean $T_{\mathrm{re}}$ just before exercise.

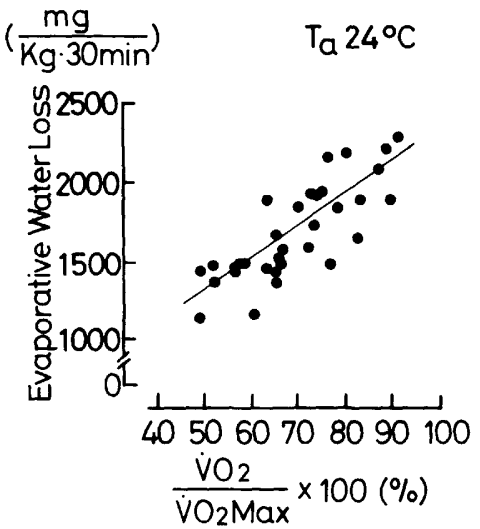

Fig. 3. Relation of evaporative water loss during $30 \mathrm{~min}$ exercise to oxygen uptake $\left(\dot{V}_{\mathrm{O}_{2}}\right)$, normalized to individual maximal oxygen uptake $\left(\dot{V}_{\mathrm{O}_{2} \max }\right)$, at an ambient temperature of $24^{\circ} \mathrm{C}$.

of $4^{\circ} \mathrm{C}$. Mean $T_{\text {re }}$ at rest before exercise was $37.7 \pm 0.3^{\circ} \mathrm{C}$ and the mean $\dot{V}_{\mathrm{O}_{2}}$ was $32.3 \pm 4.1 \mathrm{ml} /(\mathrm{min} \cdot \mathrm{kg}) . T_{\text {tail }}$ did not rise during exercise in most cases. Rate of $T_{\mathrm{re}}$ rise with exercise was lower than at other ambient temperatures. In fact, $T_{\text {re }}$ even decreased during running at low work intensities. Figure 4 shows a typical example in which $T_{\text {re }}$ dropped during exercise. Although $\dot{V}_{\mathrm{O}_{2}}$ increased a little during running from the resting value, $T_{\text {re }}$ dropped continuously at a rate of $0.02^{\circ} \mathrm{C} / \mathrm{min}$, reaching $36.9^{\circ} \mathrm{C}\left(\Delta T_{\mathrm{re}}-0.7^{\circ} \mathrm{C}\right)$ by the end of $30 \mathrm{~min}$ of exercise. After the exercise, $T_{\mathrm{re}}$ began to rise and reached $37.4^{\circ} \mathrm{C}$ in $10 \mathrm{~min}$. 


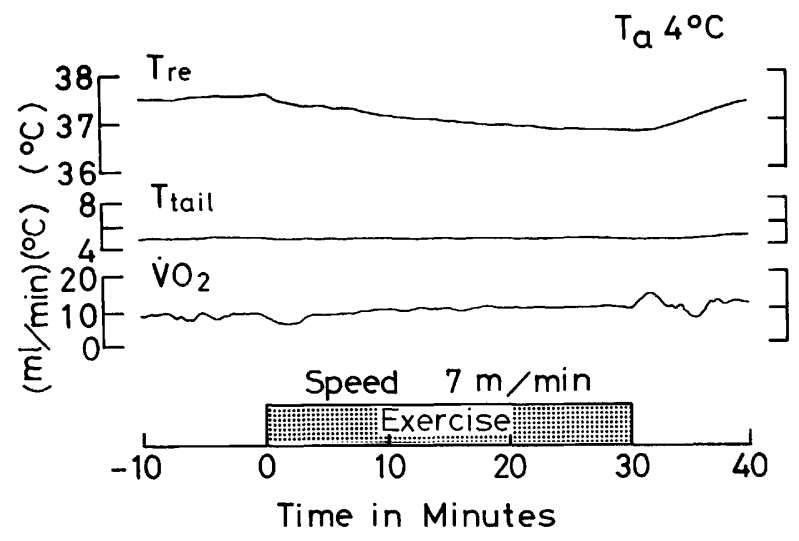

Fig. 4. Rectal temperature $\left(T_{\mathrm{re}}\right)$, tail skin temperature $\left(T_{\text {tail }}\right)$, oxygen uptake $\left(\dot{V}_{\mathrm{O}_{2}}\right)$, and absolute humidity $(\mathrm{AH})$ at rest, during exercise, and during recovery, at an ambient temperature of $4^{\circ} \mathrm{C}$.

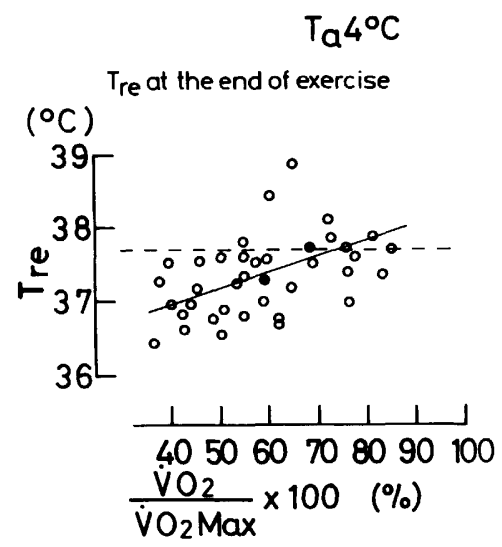

Fig. 5. Relation of rectal temperature $\left(T_{\mathrm{re}}\right)$ at the end of $30 \mathrm{~min}$ exercise to oxygen uptake $\left(\dot{V}_{\mathrm{O}_{2}}\right)$, normalized to individual maximal oxygen uptake $\left(\dot{V}_{\mathrm{O}_{2} \max }\right)$, at an ambient temperature of $4^{\circ} \mathrm{C}$. The broken line indicates mean $T_{\mathrm{re}}$ just before exercise. Open circles mean that $T_{\text {tail }}$ did not rise during the $30 \mathrm{~min}$ of running.

Figure 5 shows the relation of $T_{\text {re }}$ to work intensity at the end of exercise. $T_{\text {re }}$ was higher at higher work intensities with a regression line of $Y=36.36+0.017 X$ $(r=0.46)$. Compared to $T_{\text {re }}$ at rest (broken line), however, $T_{\text {re }}$ during exercise was seen to be dropping at work intensities below $70 \% \dot{V}_{\mathrm{O}_{2} \max }$.

At a $T_{\mathrm{a}}$ of $14^{\circ} \mathrm{C}, 35$ trials were performed. Mean $T_{\text {re }}$ at rest before exercise was $38.0 \pm 0.4^{\circ} \mathrm{C}$ and the mean $\dot{V}_{\mathrm{O}_{2}}$ was $25.9 \pm 4.0 \mathrm{ml} /(\mathrm{min} \cdot \mathrm{kg})$. As the rat ran, $T_{\text {tail }}$ rose in some instances but remained at the pre-exercise level in others. In either case, $T_{\text {re }}$ maintained a steady level in the latter half of the exercise period. The relation of $T_{\mathrm{re}}$ to work intensity at the time $T_{\text {tail }}$ began to rise is presented in Fig. 6A. $T_{\text {re }}$ rose in 
$T_{a} 14^{\circ} \mathrm{C}$

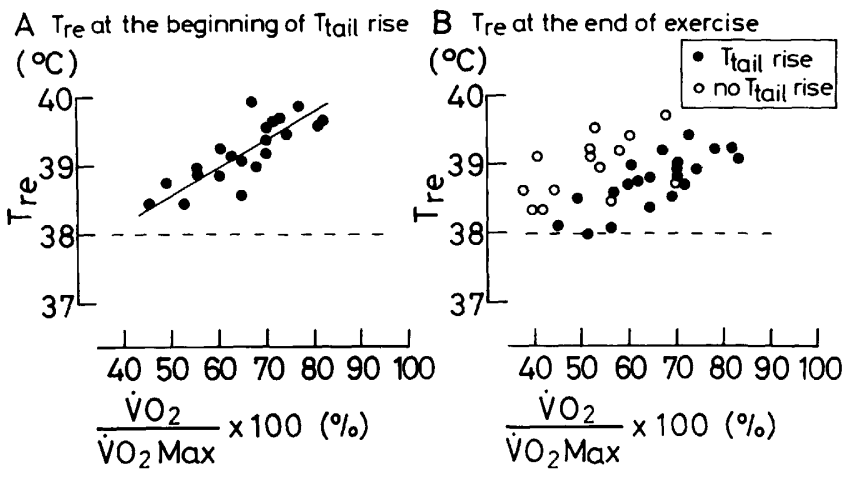

Fig. 6. Relation of rectal temperature $\left(T_{\mathrm{re}}\right)$ to oxygen uptake $\left(\dot{V}_{\mathrm{O}_{2}}\right)$ at the beginning of tail skin temperature $\left(T_{\text {tail }}\right)$ rise (A), and at the end of $30 \mathrm{~min}$ exercise (B), normalized to individual maximal oxygen uptake $\left(\dot{V}_{\mathrm{O}_{2} \max }\right)$, at an ambient temperature of $14^{\circ} \mathrm{C}$. Broken lines indicate mean $T_{\text {re }}$ just before exercise. Open circles mean that $T_{\text {tail }}$ did not rise during the $30 \mathrm{~min}$ of running.

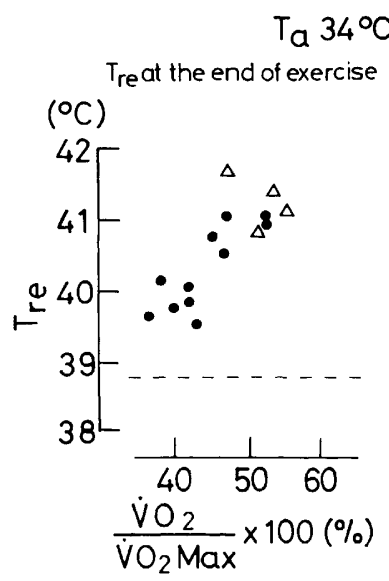

Fig. 7. Relation of rectal temperature $\left(T_{\mathrm{re}}\right)$ at the end of $30 \mathrm{~min}$ exercise to oxygen uptake $\left(\dot{V}_{\mathrm{O}_{2}}\right)$, normalized to individual maximal oxygen uptake $\left(\dot{V}_{\mathrm{O}_{2} \max }\right)$, at an ambient temperature of $34^{\circ} \mathrm{C}$. The broken line indicates mean $T_{\text {re }}$ just before exercise. Open triangles indicate $T_{\mathrm{re}}$ at the cessation of exercise in rats that could not run the entire $30 \mathrm{~min}$.

proportion to work intensity, with a regression line of $Y=36.59+0.041 X(r=0.80)$. This line was significantly different from the line at $T_{\mathrm{a}}$ of $24^{\circ} \mathrm{C}(p<0.01)$. Figure 6B shows the relation of $T_{\mathrm{re}}$ to work intensity at the end of $30 \mathrm{~min}$ exercise. The cases of $T_{\text {tail }}$ rise (closed circles) and no $T_{\text {tail }}$ rise (open circles) form distinguishable clusters. At the end of exercise at a given work intensity, $T_{\mathrm{re}}$ was higher in rats showing no $T_{\text {tail }}$ rise than in rats whose $T_{\text {tail }}$ rose. In rats exhibiting a rise in $T_{\text {tail }}$ the regression 
line was $Y=37.04+0.026 X \quad(r=0.61) ;$ otherwise the equation was $Y=$ $37.98+0.018 X(r=0.53)$.

Fifteen trials were performed at a $T_{\mathrm{a}}$ of $34^{\circ} \mathrm{C}$. Mean $T_{\text {re }}$ just before the beginning of exercise was $38.8 \pm 0.4^{\circ} \mathrm{C} . T_{\text {tail }}$ already exceeded $37^{\circ} \mathrm{C}$ at rest. In the 15 trials, rats could run for the entire $30 \mathrm{~min}$ in 11 cases. The experiments were prematurely discontinued in the remaining 4 trials, because the rats did not run even when they received continuous electrical shocks on the feet during the exercise periods. Figure 7 shows how $T_{\text {re }}$ at the end of exercise was related to work intensity. $T_{\text {re }}$ in rats that stopped running early (open triangles) exceeded $40.9^{\circ} \mathrm{C}$ in every instance, whereas rats that ran for the entire $30 \mathrm{~min}$ showed continual rises in $T_{\text {re }}$ that never leveled off.

\section{DISCUSSION}

To study the mechanism of body temperature regulation during exercise, we tried to use the rat as the model. Although the rat has been used extensively in exercise studies, regulation of body temperature during exercise in this species remains a puzzling topic for work physiologists. Earlier studies have reported the relations between work intensity and physiological variables such as deep body temperature or tail vasomotor response, but the resulting picture remains fuzzy. We decided to approach this problem by using $\dot{V}_{\mathrm{O}_{2}}$ at a neutral $T_{\mathrm{a}}$ as a standard for estimating work intensity.

During exercise for $30 \mathrm{~min}$ at a $T_{\mathrm{a}}$ of $24^{\circ} \mathrm{C}$, tail vasodilation, observed as rise in $T_{\text {tail }}$, was seen in every trial. $T_{\mathrm{re}}$ at the beginning of this tail vasodilation was proportional to work intensity and reached a maximum $\left(39.3^{\circ} \mathrm{C}\right)$ at approximately $75 \% \dot{V}_{\mathrm{O}_{2} \max }$. WILSON et al. (1978) reported that the tail became warmer during exercise at a threshold deep body temperature of $39^{\circ} \mathrm{C}$ and was independent of work intensity. $T_{\text {tail }}$ at rest before exercise was about $6^{\circ} \mathrm{C}$ higher than $T_{\mathrm{a}}$ in their study. In our study, however, the $T_{\text {tail }}$ was only a little higher than $T_{\mathrm{a}}$, indicating relative vasoconstriction. This difference of $T_{\text {tail }}$ before exercise may have been effected.

$T_{\text {tail }}$ at the end of exercise at a $T_{\mathrm{a}}$ of $24^{\circ} \mathrm{C}$ was $30-32^{\circ} \mathrm{C}$, regardless of work intensity. After the exercise, $T_{\text {tail }}$ continued to rise at higher work intensities $\left(\Delta T_{\text {tail }}\right.$ about $2^{\circ} \mathrm{C}$ ). This indicates that tail blood vassels were not fully dilated during the exercise. Previous studies in our laboratory on human subjects demonstrated that during light work in which the effects of forced evaporation and sweating were ruled out, increase in work intensities caused a proportional fall in skin temperature in larger surface area (NAKAYAMA et al., 1977, 1981). The cause of this vasoconstriction is unknown, but is regarded to be due to non-thermal factors related to exercise. The rise in core temperature during work could be explained by decreased heat loss due to persistent vasoconstrictor tone. Thus, skin temperature during exercise depended on thermoregulatory vasodilation produced by elevated body temperature and the non-thermally induced vasoconstriction. As shown in Fig. 2A, $T_{\text {re }}$ at the beginning of $T_{\text {tail }}$ rise was higher, the higher the exercise intensity. This 
result can be explained by non-thermal factors. Similarly, the fact that $T_{\text {tail }}$ continued to rise after exercise should be considered a removal of the vasoconstrictor tone.

After tail vasodilation, $T_{\text {re }}$ decreased and then remained at a steady level. Heat loss through the tail skin after vasodilation is equivalent to as much as $20 \%$ of all the heat produced in the body (RAND et al., 1965). Vasodilation in the foot occurs at practically the same time as vasodilation in the tail (THOMPSON and STEVENSON, 1965). EWL, assessed by measuring AH, increased in proportion to work intensity. Since rats do not sweat, enhancement of EWL during exercise is considered dependent mainly on ventilatory evaporation increasing due to more frequent ventilation. The possibility of cutaneous evaporation increasing with vasodilation has also been suggested (CONLEY, 1985). However, we cannot attribute all of this EWL to heat loss, because the change of $\mathrm{AH}$ in this experiment includes evaporative water from excrement and urine. During exercise at a $T_{\mathrm{a}}$ of $24^{\circ} \mathrm{C}$, rats can maintain thermal balance through the above-mentioned heat loss showing a proportional relationship between work intensity and internal temperature. The absolute value of deep body temperature at the end of exercise, especially if work intensity exceeded $75 \% \dot{V}_{\mathrm{O}_{2} \max }$, tended to be lower than in a previous study (WILSON et al., 1978). This may be attributable to such factors as duration of exercise, deep body temperature level before the start of exercise, and degree of training.

In our investigation on the relation between body temperature and $T_{\mathrm{a}}$ at various work intensities, $T_{\text {tail }}$ did not rise during exercise in most cases at a $T_{\mathrm{a}}$ of $4^{\circ} \mathrm{C}$. At a $T_{\mathrm{a}}$ of $14^{\circ} \mathrm{C}, T_{\text {tail }}$ rose during exercise in some cases but not in others. In those cases in which $T_{\text {tail }}$ rose, $T_{\text {re }}$ at the onset of $T_{\text {tail }}$ rise was about $0.4^{\circ} \mathrm{C}$ higher than at a $T_{\mathrm{a}}$ of $24^{\circ} \mathrm{C}$. In our previous study, threshold temperature to tail vasodilation induced by locally warming the preoptic area and anterior hypothalamus was affected by $T_{\mathrm{a}}$ (TANAKA et al., 1986). The results of the present study suggest that threshold $T_{\text {re }}$ to tail vasodilation during exercise is likewise affected by $T_{\mathrm{a}}$.

$T_{\text {re }}$ stabilized during exercise at a $T_{\mathrm{a}}$ of $14^{\circ} \mathrm{C}$ as well as $24^{\circ} \mathrm{C} . T_{\mathrm{re}}$ at the end of exercise was higher at a $T_{\mathrm{a}}$ of $14^{\circ} \mathrm{C}$ than $24^{\circ} \mathrm{C}$. This would be due to the suppression of the heat loss from the tail, because threshold $T_{\text {re }}$ for $T_{\text {tail }}$ rise became higher at a $T_{\mathrm{a}}$ of $14^{\circ} \mathrm{C}$ than $24^{\circ} \mathrm{C}$ at the same work intensity, and because the animals without $T_{\text {tail }}$ rise during $30 \mathrm{~min}$ session of exercise attained higher $T_{\text {re }}$ than those with $T_{\text {tail }}$ rise. On the other hand, under extreme environmental conditions such as 4 and $34^{\circ} \mathrm{C}$, rats could not maintain thermal balance during exercise. At a $T_{\mathrm{a}}$ of $4^{\circ} \mathrm{C}, T_{\text {re }}$ during exercise decreased at lower work intensities. During exercise $\dot{V}_{\mathrm{O}_{2}}$, an indicator of thermogenesis, either remained at the resting level or increased. Thus, the drop in $T_{\text {re }}$ during exercise would indicate that body heat was being lost at a greater rate than at rest. This would be due to the increase of dry heat-loss, because posture during exercise was different from that at rest. When $T_{\mathrm{a}}$ was at $34^{\circ} \mathrm{C}, T_{\mathrm{re}}$ continued to rise throughout the $30 \mathrm{~min}$ running period, even though work intensity was only $40-50 \% \dot{V}_{\mathrm{O}_{2} \max }$. Even at rest in such a hot environment in the present study, the 
rat's tail blood vessles were already dilating and the rat displayed heat-loss behavior, such as grooming or body extension, enabling $T_{\text {re }}$ to stay around $39^{\circ} \mathrm{C}$. Since heat-loss behavior is incompatible with running, autonomic heat loss must have increased in such a situation. Rats, however, do not sweat. Nor can a rat be expected to be able to control body temperature solely by respiratory evaporative water loss.

In summary, these results show that deep body temperature of rats during exercise rises in proportion to work intensity, but the extent of deep body temperature rises differs according to $T_{\mathrm{a}}$. If the rat is used as a model for studying thermoregulation in exercise, the study must carefully take $T_{\mathrm{a}}$ into account.

This study was supported in part by a Grant-in-Aid for Scientific Research from the Ministry of Education, Science and Culture of Japan (Grant No. 62480114).

\section{REFERENCES}

Adolf, E. F. (1947) Tolerance to heat and dehydration in several species of mammals. Am. J. Physiol., 151: 564-575.

CONLEY, K. E. (1985) Evaporative water loss: Thermo-regulatory requirements and measurements in the deer mouse and white rabbit. J. Comp. Physiol. (Biol.), 155: 433-436.

Gollnick, P. D. and Ianuzzo, C. D. (1968) Colonic temperature response of rats during exercise. J. Appl. Physiol., 24: 747-750.

Harri, M., Kuusela, P., and OKsanen-Rossi, R. (1982) Temperature responses of rats to treadmill exercise, and the effect of thermoregulatory capacity. Acta Physiol. Scand., 115: 79-84.

HART, J. S. and JANSKY, L. (1963) Thermogenesis due to exercise and cold in warm- and cold-acclimated rats. Can. J. Biochem. Physiol., 41: 629-634.

Nakayama, T., Ohnuki, Y., and Kanosue, K. (1981) Fall in skin temperature during exercise observed by thermography. Jpn. J. Physiol., 31: 757-762.

Nakayama, T., Ohnuki, Y., and Niwa, K. (1977) Fall in skin temperature during exercise. Jpn. J. Physiol., 27: 423-437.

Nielsen, M. (1938) Die Regulation der Körpertemperatur bei Muskel Arbeit. Scand. Arch. Physiol., 79: 193-230.

Rand, R. P., Burton, A. C., and ING, T. (1965) The tail of the rat, in temperature regulation and acclimatization. Can. J. Physiol. Pharmacol, 43: 257-267.

Saltin, B. and Hermansen, L. (1966) Esophageal, rectal, and muscle temperature during exercise. J. Appl. Physiol., 21: 1757-1762.

SonNe, B. and GalBo, H. (1980) Simultaneous determinations of metabolic and hormonal responses, heart rate, temperature and oxygen uptake in running rats. Acta Physiol. Scand., 109: 201-209.

Tanaka, H., Kanosue, K., Nakayama, T., and Shen, Z. (1986) Grooming, body extension, and vasomotor responses induced by hypothalamic warming at different ambient temperatures in rats. Physiol. Behav., 38: 145-151.

Thompson, G. E. and Stevenson, J. A. F. (1965) The temperature response of the male rat to treadmill exercise, and the effect of anterior hypothalamic lesions. Can. J. Physiol. Pharmacol., 43: 279-287. 
Wilson, N. C., Gisolfi, C. V., Farber, J., and Hinrichs, D. K. (1978) Colonic and tailskin temperature responses of the rat at selected running speeds. J. Appl. Physiol: Respir. Environ. Exercise Physiol., 44: 571-575. 